\title{
Research on Influencing Factors of Consumers' Willingness to Use Cross-border E-commerce Websites Continuously
}

\author{
Lou Xvming(First) \\ Xi'an University of Posts and Telecommunications \\ Department of economics and management \\ Xi'an, China \\ 1xmblj@163.com \\ Meng Bao(Third) \\ Xi'an University of Posts and Telecommunications \\ Department of economics and management \\ Xi'an, China \\ 278426522@qq.com
}

\author{
Bai Dan*(Second) \\ Xi'an University of Posts and Telecommunications \\ Department of economics and management Xi'an, China \\ 18710902163@163.com \\ ZhaoYanan(Third) \\ Xi'an University of Posts and Telecommunications \\ Department of economics and management Xi'an, China \\ ava_zyn@126.com
}

\begin{abstract}
Based on the technical acceptance model and the expectation confirmation model, this paper analyzes the factors affecting the willingness of consumers to use cross-border e-commerce websites, from the aspects of perceived ease of use, perceived usefulness, perceived quality (product quality, service quality, and delivery quality), perceived risk, perceived cost, and satisfaction. Then the hypothesis is verified by the structural equation model, and it is concluded that consumer perceived ease of use, perceived usefulness, perceived quality and perceived cost have a positive impact on consumer satisfaction; perceived risk has no significant impact on consumer satisfaction; consumers satisfaction has a significant positive impact on its willingness to continue using cross-border e-commerce sites.
\end{abstract}

Keywords-Cross-border E-commerce; continuance intention; structural equation model

\section{INTRODUCTION}

With the continuous improvement of people's living standards, consumers not only pay attention to the price of goods but also pay more attention to the quality. More consumers are happy to purchase foreign high-quality products through "Purchasing", "HaiTao", etc., meaning that more Chinese consumers purchase foreign goods on cross-border e-commerce websites, so the increasing purchasing power caused multiple part's attention. Many e-commerce companies are involved in cross-border e-commerce, while some traditional express delivery companies rely on their logistics advantages to deploy cross-border e-commerce, and cross-border e-commerce in China is booming.

At present, cross-border e-commerce website in china is in a period of development and consumer groups are not clear. Therefore, its primary task is to continue to attract new customers, and to retain the oldest customers to the maximum extent, so as to continue to maintain competitiveness. Therefore, how to improve customer satisfaction, so that customers continue to use the site to purchase goods has become a key point for the healthy and rapid development of cross-border e-commerce sites.

The rapid development of cross-border e-commerce in recent years has become a hot topic in the field of academic research. The focus is mainly on the status quo, development trend, legislation, supervision, taxation, logistics, and cost of cross-border e-commerce. However, there is a lack of research on consumers' willingness to continue to use, and the objects of the research at home and abroad mainly focus on traditional e-commerce, $\mathrm{O} 2 \mathrm{O}$ e-commerce, mobile e-commerce, and mobile device payments. Since the continuous use intention of consumers is of great significance to the sustainable development of cross-border e-commerce, this paper conducts empirical research on the influencing factors of consumers' continuous use intention from the perspective of cross-border e-commerce. By analyzing the current status of cross-border e-commerce research, combining with technology acceptance theory, and continuous use theory related models, we construct a theoretical model of the influencing factors of consumers' willingness to use cross-border e-commerce websites continuously. And use EXCEL and SPSS to validate the model. Finally, give advice on how to strengthen the operational capabilities and influence of cross-border e-commerce companies, and provide reference for other companies preparing to participate in cross-border e-commerce.

\section{RELEVANT RESEARCH REVIEW}

\section{A. Technology Acceptance Theory}

The Technology Acceptance Model (TAM) was proposed by Davis (1989). He used rational behavior theory as a theoretical framework to construct a new model. The model was originally designed to explain the factors that influence users' wide acceptance of computers. The technology acceptance model believes that personal attitudes toward using technology determine behavioral intentions, and individual behavioral intentions determine the actual behavior of users. 
Perceived usefulness and ease of use work together on personal attitudes. Perceived ease of use and external variables work together to perceived usefulness, and external variables also act on perceived ease of use ${ }^{[1]}$. See Fig. 1.

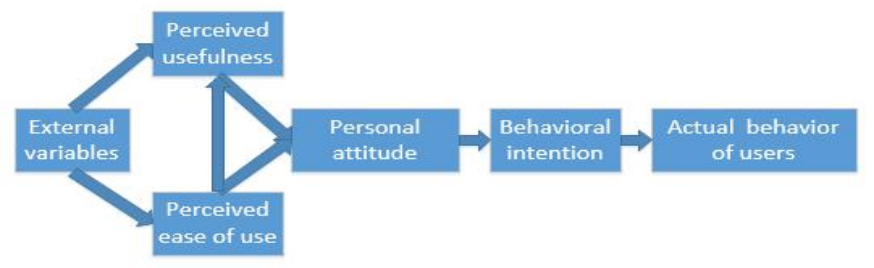

Fig. 1. Technology Acceptance Theory

Among them, perceived usefulness refers to the individual's sense of improvement in the level of performance after using the technology. Perceived ease of use refers to an individual's expectation of ease of use of the technology. External variables are factors that influence the behavior of individuals using the system, including user and system characteristics, the external environment, and other factors.

Since the theory of technology acceptance is a model for users to accept information systems, the theory is highly targeted. Many scholars have studied the will and behavior of users using various information systems by adding different variables based on this theory. Some scholars also study the user's willingness and behavior of continuous use of various information systems by adding variables such as social cognitive theory, fluid theory, and expectation confirmation theory.

\section{B. User Continued Usage Theory}

The Expectation Confirmation Model (ECM) [2] was proposed by Bhattacherjee (2001). When he was studying the user's continuous use of information systems, he used Oliver's expectation confirmation theory of consumer behavior as the theoretical basis. The model includes a total of 4 variables: (1) Expected confirmation: The degree of compliance felt by the user after using the information system and the expected result of the user before using the information system. (2) Perceived usefulness: The extent to which users feel their own performance improvements after using the information system. (3) Satisfaction: The overall satisfaction of the user with the information system after using the information system. (4) Willingness to continue using: After using the information system, the user, in combination with his/her own use situation, demonstrated that he would continue to use the information system ${ }^{[3]}$. The relationship between the four variables is shown in Fig.2.

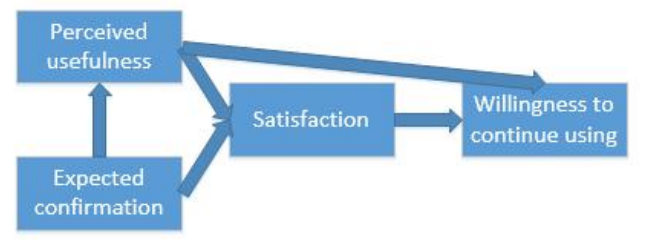

Fig. 2. Expectation Confirmation Model
After proposing the expectation confirmation model, many scholars applied the theory to the user's willingness and behavior research on the continuous use of information systems. However, due to the different characteristics of each information system, the model will be modified accordingly when applying the expected validation model, which can be studied by adding other variables or combining other theories. Therefore, this paper also uses the Expectation Confirmation Model to study the consumer's intent to continue using cross-border e-commerce sites.

By combing the existing literature, the perceived usefulness is identified as one of the influencing factors. The technology acceptance model considers that the higher the individual's perception of the information system, the stronger the behavioral intention. However, the user's initial experience is the main focus of these influencing factors. The user's feeling after use is more concerned with the influencing factors in the expectation confirmation theory. The expectation confirmation theory believes that the satisfaction is affected by the degree of expected confirmation after use, and the willingness to continue using it. It is also affected by the degree of expected confirmation after use. As the usage time changes, user expectations also change. Therefore, post-consumer expectations (perceived usefulness) are used as an influencing factor, and perceived usefulness is affected by the degree of expected confirmation.

This paper focuses on consumers' willingness to continue to use cross-border e-commerce sites. Combined with the characteristics of cross-border e-commerce, it is believed that the various factors before the initial use of consumers and the degree of recognition after use have a significant impact on consumers' continued use of cross-border e-commerce websites Based on the above literature and theoretical analysis, TAM and ECM are finally used as the important theoretical basis for studying the willingness of consumers to continue to use cross-border e-commerce websites.

\section{RESEARCH MODELS AND ASSUMPTIONS}

\section{A. Model Construction}

This paper mainly studies the influencing factors of consumers' willingness to continue to use cross-border e-commerce websites. The willingness to continue to use behavior is generally affected by factors such as the willingness to use for the first time, the degree of expectation of the use behavior after initial use, satisfaction, and other factors. The object of the action is cross-border e-commerce websites.

Analyze the influencing factors of initial use intention. Learn from TAM's perceptual ease-of-use and perceive useful variables. Analyze the willingness to use continuously, and use the ECM's perception of usefulness, expectation confirmation, satisfaction, and continuous use willingness variables. Among them, expectation confirmation is defined as perceived quality. There are three dimensions: product quality, service quality, and distribution quality. Because consumers use cross-border e-commerce websites, which may cause personal privacy, payment and other risks, this paper increases the perceived risk factors. At the same time, the time cost and price cost incurred 
by consumers when shopping on cross-border e-commerce websites will be higher than that of general e-commerce websites, thus increasing the perceived cost factor. Combined with the actual situation and existing problems of Chinese consumers using cross-border e-commerce websites, the overall research model of consumers' willingness to continue to use cross-border e-commerce websites is proposed. See Fig.3.

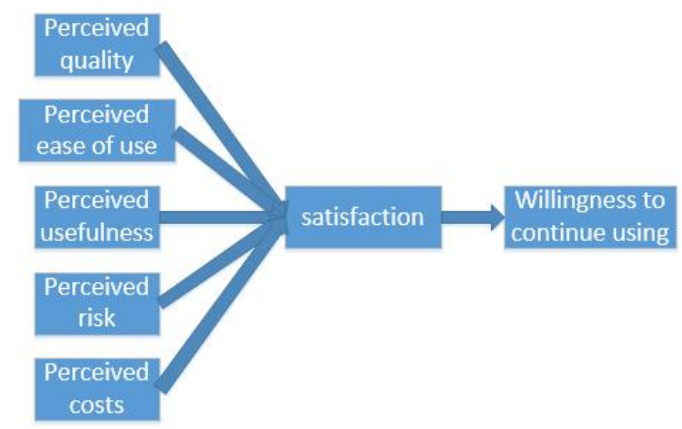

Fig. 3. Consumers continue to use cross-border e-commerce website willingness model

\section{B. Research hypothesis}

The research model uses perceptual ease of use, perceived usefulness, perceptual quality, perceived risk, and perceived cost as independent variables, satisfaction as mediator variable, and continuous use willingness as dependent variable.

1) Assume the relationship between independent variables and mediating variables

Davis (1989), Liu Wenjun, Ding Lin, Wang Cuibo (2015) ${ }^{[3]}$, Qi Hongyun (2011) ${ }^{[4]}$, Qiao Jun, Kang Yulan (2015) ${ }^{[5]}$ and other scholars passed information systems, electricity providers, hotel online research in the areas of reservations, B2C shopping sites, etc., confirms that the user's perceived ease of use has a very significant effect on their satisfaction, so it is assumed that:

H1: Consumer's perceived ease of use has a positive effect on their satisfaction

Davis (1989), Bhattacherjee (2001), Liu Renjing, Chai Jing $(2013)^{[6]}$, Chen Meiling, Bai Xingrui $(2014)^{[7]}$, Dai Bao, Liu Yezheng ${ }^{[8]}$, Zhao Qing, Liang Gongqian (2013) $)^{[9]}$.Many scholars have confirmed that perceived usefulness has a very significant impact on user satisfaction through research in areas such as information systems, the Internet, SNS social networks, mobile learning, micro-channels, and mobile commerce. Therefore, it is assumed that:

H2: Consumer perceived usefulness has a positive effect on consumer satisfaction

Perceived quality is divided into three dimensions: perceived product quality, service quality, and distribution quality to better analyze the impact of perceived quality on consumer satisfaction. The effects of these three dimensions on satisfaction are discussed separately here.

Qiao Jun, Kang Yulan (2015), Chun-chun Lin (2011) ${ }^{[10]}$, Xie Peihong (2011) $)^{[11]}$, Zhang Shengliang, Li Xiaodong (2013) $)^{[12]}$, Ning Changhui, Hu Changchun (2015) and many other scholars Through the study of different objects, it is concluded that the quality of the product has a very important impact on user satisfaction. Therefore, it is assumed that:

H3a: Product quality has a positive effect on consumer satisfaction

$\mathrm{Xu}$ Donglei $(2010)^{[13]}$, Dai Lei(2011) ${ }^{[14]}, \quad$ Yan Hongyun(2011) and many other scholars have verified the quality of service to users through research on e-commerce, mobile electronic certification, and online hotel reservations. The degree has a very significant effect, so assume that:

H3b: Service quality has a positive effect on consumer satisfaction

Many scholars such as Chun-chun Lin (2011), Li Pei (2015) [15], Zhou Jianjun (2012) [16], Xie Peihong (2011) and many others have studied different subjects. It is concluded that the distribution quality has a very important influence on the user's satisfaction, so it is assumed that:

H3c: Distribution quality has a positive effect on consumer satisfaction

Liu X, He M (2008) ${ }^{[17]}$, Zhao Peng, Zhang Jinchao (2014), Zhao Qing, Liang Gongqian (2013) and many other scholars have learned from various fields such as e-commerce, online storage services, and mobile e-commerce. Consumer perceived risk has a strong negative impact on user satisfaction, so assume that:

H4: Consumer perceived risk has a negative effect on their satisfaction

Jin Liyin $(2008)^{[18]}$, Zhang Chubing, Chen Yafeng (2011) ${ }^{[19]}$, Zhao Qing, Liang Gongqian (2013) and many other scholars have come to the conclusion that perception costs have a very important impact on user satisfaction through the study of different objects. , so assume that:

H5: Consumer perceived costs have a positive effect on their satisfaction

2) Assume the relationship between mediating variables and dependent variables

Bhattacherjee (2001), Liu Renjing, Chai Jing (2013), Chen Meiling, Bai Xingrui (2014), Zhao Peng, Zhang Jinchao (2014), Sun Jianjun, Yu Lei, Liu Hong (2013) and many other scholars have studied various fields such as the Internet, SNS social networks, mobile learning, online storage, and video networks. The user's satisfaction was confirmed to be used for its continuous use intention, so it is assumed that:

H6: Consumer satisfaction has a positive effect on their willingness to continue using

\section{RESEARCH DESIGN AND DATA ANALYSIS}

\section{A. Questionnaire design}

The questionnaire is mainly divided into three parts.

1) Prompting information, introducing the survey background and completing instructions.

2) Filling in the basic information of the person, such as age, gender, income status, education, online shopping history, cross-border e-commerce website shopping, etc.

3) The main part of the questionnaire, the perception of perceived ease of use, perceived usefulness, perceived quality 
(commodity quality, service quality, delivery quality) perceived risk, perceived cost, consumer satisfaction, and consumer Will continue using)these nine variables to measure.
The study drew on mature tables and metric scales to improve the credibility and validity of collected data.

TABLE I. RESEARCH VARIABLES AND MEASUREMENT INDICATORS

\begin{tabular}{|c|c|c|}
\hline Variables & Indicators & Measurement item \\
\hline \multirow{3}{*}{ Perceived ease of use } & A1 & I can easily find the desired product on the cross-border e-commerce website \\
\hline & A2 & The interface of the cross-border e-commerce website is easy to understand \\
\hline & A3 & The transaction process of this cross-border e-commerce website is simple. \\
\hline \multirow{4}{*}{ Perceived usefulness } & $\mathrm{B} 1$ & I think it's easier to shop on this cross-border e-commerce site \\
\hline & $\mathrm{B} 2$ & I think that shopping on this cross-border e-commerce website will save time \\
\hline & B3 & I think purchasing goods on this cross-border e-commerce website can improve my quality of life \\
\hline & B4 & The cross-border e-commerce website allows me to purchase goods at more favorable prices \\
\hline \multirow{3}{*}{ Product quality } & $\mathrm{C} 1$ & The goods sold by the cross-border e-commerce website match the information provided by the website \\
\hline & $\mathrm{C} 2$ & The quality of the products sold by the cross-border e-commerce website matches my expectations \\
\hline & $\mathrm{C} 3$ & The goods sold by the cross-border e-commerce website are genuine \\
\hline \multirow{3}{*}{ Service quality } & D1 & The cross-border e-commerce website has a comprehensive shopping protection system and measures \\
\hline & $\mathrm{D} 2$ & I think the customer service is very considerate when shopping on this cross-border e-commerce website. \\
\hline & D3 & I think after the cross-border e-commerce website shopping, the business service is very good \\
\hline \multirow{4}{*}{ Distribution quality } & F1 & Business can timely delivery \\
\hline & F2 & Goods can be delivered within the promised time \\
\hline & F3 & The merchant's delivery method meets my requirements \\
\hline & F4 & The package of goods delivered is in good condition \\
\hline \multirow{3}{*}{ Perceived risk } & G1 & Worried about the risk of leaking personal information \\
\hline & G2 & Concerned about security risks in the payment process \\
\hline & G3 & Concerned about the financial losses caused by improper operations in the payment process \\
\hline \multirow{3}{*}{ Perceived cost } & $\mathrm{H} 1$ & I don't think it takes too much time and effort to use this cross-border e-commerce website \\
\hline & $\mathrm{H} 2$ & I think the price of the product is reasonable because of the exchange rate \\
\hline & $\mathrm{H} 3$ & I think that due to the shipment of goods from abroad, the shipping time is within my expectation. \\
\hline \multirow{3}{*}{ Satisfaction } & I1 & Overall satisfaction with this shopping experience \\
\hline & $\mathrm{I} 2$ & Satisfaction with the services of the cross-border e-commerce website and merchants \\
\hline & $\mathrm{I} 3$ & Satisfied with the purchased product \\
\hline \multirow{3}{*}{ Willingness to continue using } & $\mathrm{J} 1$ & When there are similar consumer demand, I will give priority to this website \\
\hline & $\mathrm{J} 2$ & I will increase the frequency of using this cross-border e-commerce website \\
\hline & $\mathrm{J} 3$ & I would like to recommend to others to buy goods on this cross-border e-commerce website \\
\hline
\end{tabular}

This study uses Likert 5 components to measure each of these variables. The user selects the match from the five options of complete agreement, somewhat agreement, uncertainty, a bit of disagreement, and complete disagreement. After 70 parts of the small sample questionnaire for project test reliability test and validity test, remove $\mathrm{B} 3, \mathrm{C} 3$ items, retained the other key questions to form a new questionnaire, then large-scale release.

\section{B. Data Collection}

The questionnaire was distributed in two ways: paper questionnaire and electronic questionnaire. The questionnaire was anonymous and 223 copies were collected, including 65 papers, 158 electrons and 210 valid questionnaires. The effective recovery rate of the questionnaire was $94.17 \%$.

\section{Data Analysis}

This section conducts an empirical analysis of the model. The collected data were processed first, and correlations, multiple collinearity analyses, and multiple regression analysis were performed on each variable. Then carry out hypothesis testing, including model fitting test and impact path analysis. Finally, analyze the results and correct the model.

\section{1) Sample Descriptive Statistical Analysis}

a) Descriptive analysis of demographic variables: The proportion of women and men in this survey was about $65.6 \%$ and $34.4 \%$. It shows that there are more women online shopping. The ages are mainly concentrated in the ages of $18-25$ and 26-35, accounting for about $58.1 \%$ and $33.7 \%$ respectively. The object of this survey was younger. In academic qualifications, undergraduate education accounted for $45.24 \%$. Followed by graduates and above accounted for $38.1 \%$, indicating that most of the online shopping population in undergraduate or graduate education. The monthly income is concentrated in 3000 5000 and 5000 8000 yuan, and $3000 \sim 5000$ yuan accounts for $32.38 \%$. After analysis, most of these are white collar graduates. 5,000 to 8,000 yuan accounted for $26.19 \%$, most of these graduates are white-collar graduates. Those under 1,000 yuan account for $18.57 \%$, most of them are undergraduates and postgraduates. It shows that most of the objects of this survey are graduates who have already worked.

b) Analysis of cross-border e-commerce website usage: In this survey, the average number of people who spend 10 to 30 hours online per week is about $40.47 \%$, and the average number of people who spend 30 to 50 hours per week on the Internet is about $36.19 \%$, which indicates that most of the objects of this survey have strong dependence on the network. The average monthly consumption of cross-border e-commerce websites is concentrated in 2 to 5 times, accounting for $76.19 \%$ of the total, indicating that most of the samples in this survey have been used to purchase goods through cross-border e-commerce websites. The total monthly online shopping 
spending is concentrated at 100 to 500 yuan, accounting for about $46.19 \%$. The proportion of spending $500-1000$ yuan is about $31.43 \%$, ranking second. The categories of goods purchased are concentrated on clothing shoes, cosmetics, bags, food and health care, which is related to the young white-collar workers or students in this research. This group is familiar with online shopping.

\section{2) Model Hypothesis Testing}

In this paper, the structural equation model is used to test the accuracy of the hypothesis model, and AMOS is used to analyze the data to verify the research model and related hypotheses.

\section{a) Building a Structural Equation Model:}

Constructing structural equations in AMOS, including perceived ease of use (A), perceived usefulness (B), product quality (C), service quality (D), distribution quality (F), perceived cost $(\mathrm{G})$, perceived risk $(\mathrm{H})$, consumer satisfaction (I), willingness to continue using $(\mathrm{J})$, the structural equation model of the fitted output is shown in Fig.4.

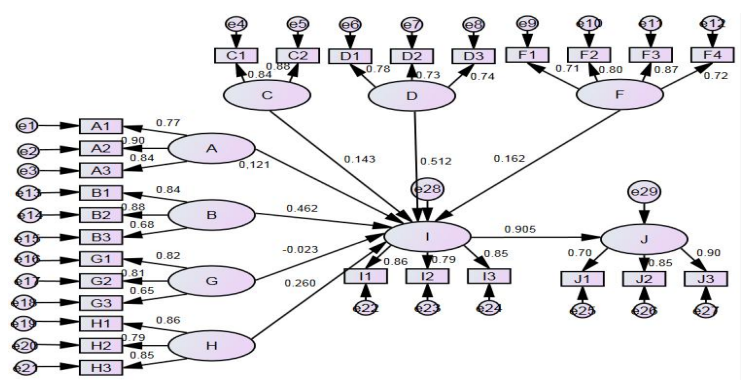

Fig. 4. Construction of Structural Equation Model

\section{b) Model Fit Test:}

The model fit test is an evaluation of the acceptability of the theoretical model. The most common way is to evaluate the size of the fit index. Fitting constants commonly used include absolute index: the ratio of degrees of freedom chi-square $\left(\chi^{2} / \mathrm{df}\right)$, the root mean square error of approximation (RMESA) goodness of fit index (GFI). Relative index: Normative fit index (NFI), comparative fit index (CFI). The model fitting test results are shown in Table II.

TABLE II. MODEL FIT TEST

\begin{tabular}{clcl}
\hline Indicators & Actual value & Reference & conclusion \\
\hline$\chi^{2} / \mathrm{df}$ & 2.236 & $\langle 3$ & better \\
RMSEA & 0.023 & $\langle 0.1$ & better \\
GFI & 0.893 & $>0.9$ & acceptable \\
NFI & 0.901 & $>0.9$ & better \\
CFI & 0.928 & \rangle 0.9 & better \\
\hline
\end{tabular}

Through analysis, the actual values of the four indicators $\chi^{2} / \mathrm{df}$, RMSEA, NFI, and CFI are within a reasonable range. The actual value of this indicator of NFI is 0.893 , which is slightly less than the reference value of 0.9 . Considering that the difference is small and the sample size is large, we think this indicator is acceptable. Although the fitting index of the model does not meet the reference value perfectly, it has basically met the requirements. Therefore, we believe that the model has a good degree of fit.

\section{c) Model influence path analysis:}

In this study, the maximum likelihood method is used to analyze the path of the model and then verify the hypothesis. The path coefficients and significance results of each item are shown in Table III.

TABLE III. ESTIMATED RESULTS OF MODEL IMPACT PATHS

\begin{tabular}{cllllll}
\hline Hypothesis & Factor relations & Path coefficient standard value & T value & P value & Significance & conclusion \\
\hline $\mathrm{H} 1$ & $\mathrm{~A} \rightarrow \mathrm{I}$ & 0.121 & 3.70 & 0.03 & Significant & support \\
$\mathrm{H} 2$ & $\mathrm{~B} \rightarrow \mathrm{I}$ & 0.462 & 4.16 & $* * *$ & Significant & support \\
$\mathrm{H} 3 \mathrm{a}$ & $\mathrm{C} \rightarrow \mathrm{I}$ & 0.143 & 3.11 & $* * *$ & Significant & support \\
\hline $\mathrm{H} 3 \mathrm{~b}$ & $\mathrm{D} \rightarrow \mathrm{I}$ & 0.512 & 9.07 & $* * *$ & Significant & support \\
$\mathrm{H} 3 \mathrm{c}$ & $\mathrm{F} \rightarrow \mathrm{I}$ & 0.162 & 8.81 & $* * *$ & Significant & support \\
$\mathrm{H} 4$ & $\mathrm{G} \rightarrow \mathrm{I}$ & -0.023 & -0.02 & 0.67 & not significant & not support \\
$\mathrm{H} 5$ & $\mathrm{H} \rightarrow \mathrm{I}$ & 0.260 & 1.97 & $* * *$ & Significant & support \\
$\mathrm{H} 6$ & $\mathrm{I} \rightarrow \mathrm{I}$ & 0.905 & 3.78 & $* * *$ & Significant & support \\
\hline
\end{tabular}

From the above table, the structural equation model path diagram is obtained as follows.

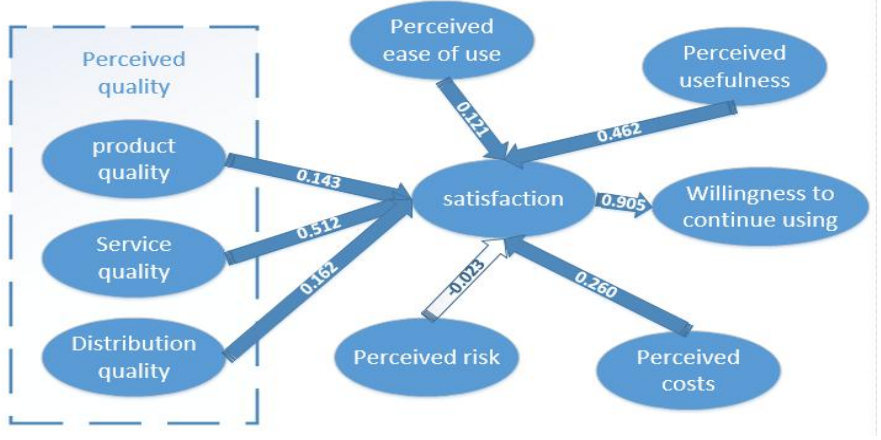

Fig. 5. Structural equation model path diagram 


\section{3) Test Results and Analysis}

a) Test results: Through the verification of the structural equation model, only one of the eight hypotheses in the study was not established, that is, perceived risk has a negative impact on consumer satisfaction, and other assumptions are true.

b) Analysis of test results: The relationship between consumer satisfaction and their respective variables: perceived ease of use, perceived usefulness, product quality, service quality, distribution quality, and perceived cost have a significant positive impact on consumer satisfaction. The impact path coefficients are: $0.121,0.462,0.428,0.143,0.512$, 0.260 .The quality of service under the perceived quality dimension has the greatest impact on consumer satisfaction ( $\mathrm{H} 3 \mathrm{~b}$ is established). Next are perceived usefulness ( $\mathrm{H} 2$ is established), perceived cost (H5 is established), distribution quality (H3c is established), product quality (H3a is established), and finally perceived ease of use (H1 is established). However, perceived risk has no significant effect on consumer satisfaction ( $\mathrm{H} 4$ does not hold). As the mainstream cross-border e-commerce websites currently in use have relatively sound system security and have a stable customer base, the long-term use of consumers has reduced their risk perception. Therefore, perceived risk has no significant effect on satisfaction.

The relationship between consumer satisfaction and dependent variables: Consumer satisfaction significantly positively affects the willingness to continue using, with a path coefficient of 0.906 , so H6 is established.

\section{4) Model Correction}

Since the hypothesis $\mathrm{H} 4$ is not valid in the research model, the original model is modified to obtain the final model. See Fig.6.

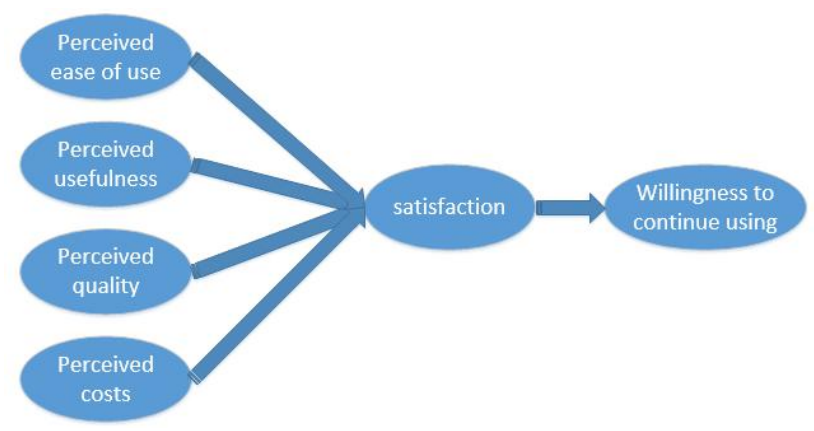

Fig. 6. Consumers continue to use cross-border e-commerce website willingness model

\section{V.CONCLUSION}

\section{A. Main conclusions}

- This paper studies the influencing factors of consumers' willingness to continue to use cross-border e-commerce websites and concludes that consumer satisfaction directly affects consumers' willingness to use continuously.

- The variables of perceived ease of use, perceived usefulness, product quality, service quality, distribution quality, and perceived cost affect consumer satisfaction and then affect the consumer's willingness to continue using.

- Among them, service quality has the greatest impact, followed by perceived usefulness, perceived cost, distribution quality, product quality, and perceived ease of use.

- Perceived risk has no direct effect on consumer satisfaction.

\section{B. Management Suggestions}

1) Improve quality and pay attention to customers: According to the research conclusions, three suggestions are proposed for the operation and management of cross-border e-commerce websites:

a) In terms of service quality: Establish a reasonable and effective complaint mechanism and punishment mechanism.

b) In terms of product quality: If consumers buy fake or defective products, the sellers should be punished and the consumers should be compensated. In addition, the cross-border e-commerce website should cooperate with more quality brands on the basis of understanding consumer demand in order to increase consumer satisfaction, thereby enabling consumers to rely on the site and achieve continuous purchasing.

c) In terms of distribution management: Whether it is through international logistics or from the bonded area, businesses and websites should cooperate with more logistics companies to provide consumers with more choices. At the same time, after the consumer places an order, the goods can be delivered as early as possible, and the goods are reasonably packaged to ensure that the goods are packaged in the hands of the consumers after long-distance transportation.

2) All-round display of goods, to improve the perceived usefulness: The cross-border e-commerce website needs to find a large number of potential customer groups and make them understand the website; translate the content of the product as accurately as possible; and cooperate with various beauties, health, and fashion APPs to display the products sold in multiple directions; increase consumer awareness and preference of foreign products, and constantly increase their perceived usefulness.

3) Improve the cost advantage of cross-border e-commerce: Consumers choose cross-border e-commerce sites to purchase overseas goods, largely because of the higher cost-effectiveness of purchasing overseas goods through this method. They should purchase large quantities to reduce costs and reduce taxes through centralized entry. Under the premise of ensuring authenticity, there is a lower price to enhance consumers' willingness to continue to use.

4) Reasonable design to improve consumer ease of use: The website design should be clear and easy to operate. When introducing merchandise, it is necessary to completely translate and explain the conditions of the merchandise, so that 
consumers can fully understand the merchandise and can easily purchase it.

\section{REFERENCES}

[1] Davis F. Perceived usefulness, perceived ease of use, and user acceptance of information technology[J]. MIS Quarte, 1989, 13(3):319-341.

[2] Koufaris M. Applying the Technology Acceptance Model and Flow Theory to Online Consumer Behavior. [J]Information Systems Research, 2002,13(2):205-223.

[3] Bhattacherjee. A. Understanding information systems continuance: an expectation confirmation model [J] MIS Quarter,2001,25(3):351-370.

[4] Yan Hongyun. Research on the impact of e-service quality on online satisfaction of hotel customers[J]. Business Economics. 2011, (9): 36-40.(In Chinese)

[5] QIA Jun, KANG Yulan. Research on the Influencing Factors of Customer Satisfaction of Domestic B2C Shopping Websites: An Empirical Analysis Based on Jingdong Mall [J]. Journal of Nanjing University of Finance and Economics.2015,5:87-94. (In Chinese)

[6] Liu Renjing, Chai Miao. Research on the Influencing Factors of Sustainable Use Behavior of Individual Users of SNS Social Network [J]. Soft Science. 2013, (4): 132-135. (In Chinese)

[7] Chen Meiling, Bai Xingrui, Lin Yan. Empirical study on the influencing factors of mobile learners' continuous use behavior[J]. China Distance Education. 2014,(12):41-47. (In Chinese)

[8] DAI Bao, LIU Yezheng's Willingness to Use Willingness Based on Expectation Confirmation Model, Social Presence, and Flow Experience[J]. Management Research, 2015, 3:19-23. (In Chinese)
[9] Zhao Qing, Liang Gongqian, Wang Qun. Research on Continuous Use Model of Mobile Business Users[J].Science and Technology Management Research, 2013,(1):249-253. (In Chinese)

[10] Chun-Chun Lin, Hsueh-Ying Wu \& Yong- Fu Chang .The Critical Factors Impact on Online Customer Satisfaction[J].Procedia Computer Science, 20113:276-281.

[11] Xie Peihong, Geng Hongmei, Wei Nongjian, Liu Xia. Empirical research on the influencing factors of customer satisfaction in China's B2C e-commerce during the transition period [J].Science Research Management.2011,2:109-117. (In Chinese)

[12] Zhang Shengliang, Li Xiaodong. Research on Influencing Factors of Customer Satisfaction in Online Shopping[J]. Journal of Tianjin University: Social Science Edition. 2013, (2): 109-115. (In Chinese)

[13] Xu Donglei. Analysis of Customer Satisfaction in C2C E-commerce [D] Hefei: Anhui University 2010. (In Chinese)

[14] Dai Lei, Xu Boyi. Research on Public Continuing Use Behavior of Mobile E-government [J]. Journal of Information. 2011, (1): 186-189. (In Chinese)

[15] Li Pei. Research on the impact of B2C e-commerce distribution service on customer satisfaction [D]. Electronics Liaoning University, 2015. (In Chinese)

[16] Zhou Jianjun. The influence of distribution on B2C e-commerce customer satisfaction and evaluation index system [J]. Logistics Technology. 2012,9:62-65. (In Chinese)

[17] Liu X, He M, Gao F. An Empirical Study of Online Shopping Customer Satisfaction in China: A Holistic Perspective [J]. International Journal of Retail \& Distribution Management, 2008, 36:919-940.

[18] Jin Liyin. The effect of service switching cost on customer loyalty - the moderating effect of satisfaction and the attractiveness of alternatives [J]. Chinese Journal of Management. 2008, 6: 912-920. (In Chinese)

[19] Zhang Chubing, Chen Yafeng, Yi Munong. Empirical research on the influence of four dimensions of conversion cost on customer retention [J]. Economic Management, 2011, (3): 93-100. (In Chinese) 